$\mathbf{E} \cdot \mathbf{R} \cdot \mathbf{R} \cdot \mathbf{A} \cdot \mathbf{T} \cdot \mathbf{U} \cdot \mathbf{M}$

\title{
An Inadequate Weld Repair and a Consequent Rupture of a Pressure Vessel
}

Tim A. Jur $\cdot$ Kyle T. Minden

Published online: 28 September 2007

(c) ASM International 2007

Erratum to: J Fail. Anal. and Preven.

DOI 10.1007/s11668-007-9057-x

Dimensions given in brackets in the figure captions of the online html version of this article were included unintentionally. Please disregard.

The online version of the original article can be found under doi: 10.1007/s11668-007-9057-x.

T. A. Jur $(\bowtie)$

Engineering Design and Testing Corp., Columbia District Office,

PO Box 8027, Columbia, SC 29202-8027, USA

e-mail: tajur@edtengineers.com

K. T. Minden

Engineering Design and Testing Corp., Kansas City District Office, PO Box 40026, Overland Park, KS 66204-0926, USA

e-mail: ktminden@edtengineers.com 